Osmaniye Korkut Ata University
Fen Bilimleri Enstitüsü Dergisi

\title{
Keban Baraj Gölü Seviye Değişiminin ANFİS ve Destek Vektör Makineleri ile Tahmini
}

\author{
Hatice ARSLAN ${ }^{1}$, Fatih ÜNEŞ ${ }^{2}$, Mustafa DEMİRCi ${ }^{3}$, Bestami TAŞAR ${ }^{4 *}$, Ada YILMAZ \\ ${ }^{1-5}$ İskenderun Teknik Üniversitesi, Müh. ve Doğa Bil. Fakültesi, İnşaat Müh. Bölümü, 31200, Hatay
}

${ }^{1}$ https://orcid.org/0000-0001-7989-2862

${ }^{2}$ https://orcid.org/0000-0001-5751-6970

${ }^{3}$ https://orcid.org/0000-0002-3249-2586

${ }^{4}$ https://orcid.org/0000-0003-4842-3937

${ }^{5}$ https://orcid.org/0000-0002-8595-2208

*Sorumlu yazar: bestami.tasar@iste.edu.tr

\begin{tabular}{|c|c|}
\hline Araştırma Makalesi & ÖZET \\
\hline $\begin{array}{l}\text { Makale Tarihçesi: } \\
\text { Geliş tarihi: } 4 \text { Haziran } 2020 \\
\text { Kabul tarihi: } 7 \text { Ağustos } 2020 \\
\text { Online Yayınlanma: Aralık } 2020\end{array}$ & $\begin{array}{l}\text { Bir baraj haznesindeki su seviyesinin doğru tahmini, su kaynaklarının yönetimini } \\
\text { optimize etmek için önemlidir. Bu çalışmada, Adaptif Sinirsel Bulanık Çıkarım } \\
\text { sistemi (ANFIS) ve Destek Vektör Makineleri (DVM) metotları kullanılarak bir } \\
\text { baraj haznesindeki su seviyesi değişimi tahmin edilmiştir. Klasik bir yöntem olan } \\
\text { Cokllän }\end{array}$ \\
\hline $\begin{array}{l}\text { Anahtar Kelimeler: } \\
\text { Baraj } \\
\text { Bulanık mantık } \\
\text { Su seviyesi } \\
\text { Destek vektör makineleri } \\
\text { Tahmin }\end{array}$ & $\begin{array}{l}\text { sonuçları ile karşılaştırılmıştır. Bu çalışmada girdi verileri olarak enerji gayesi için } \\
\text { su sarfiyatı, günlük toplam su sarfiyatı ve toplam buharlaşma miktarı değişkenleri } \\
\text { kullanılarak günlük hazne seviyesi tahmin edilmiştir. Uygulama alanı olarak } \\
\text { Türkiye'nin Doğu Anadolu Bölgesinde yer alan Keban Barajı ve haznesi } \\
\text { seçilmiştir. Sonuçlar değerlendirildiğinde, tüm model sonuçlarının baraj hazne } \\
\text { seviye tahmininde başarılı olduğu ve birbirine yakın sonuçlar verdiği gözlenmiştir. }\end{array}$ \\
\hline
\end{tabular}

\section{Estimation of Keban Dam Lake Level Change Using ANFIS and Support Vector Machines}

\section{Research Article}

\section{Article History}

Received: 4 June 2020

Accepted: 7 August 2020

Published online: December 2020

\section{Keywords:}

Dam

Fuzzy logic

Water level

Support vector machines

Estimation

\begin{abstract}
The correct estimation of the water level in a reservoir is important to optimize the management of water resources. In this study, the water level change in a reservoir was estimated using the Adaptive Neuro-Fuzzy Inference System (ANFIS) and Support Vector Machines (SVM) method. It is compared with the results obtained by the conventional method, Multi Linear Regression Analysis (MLR) method, and the actual observation results. In this study, as the input data, daily tank level was estimated by using variables of energy gauge, daily total water consumption and total evaporation amount. Keban Dam and its reservoir located in the Eastern Anatolia Region of Turkey were selected as the application area. When the results were evaluated, it was observed that the results of all models were successful in dam reservoir level estimation and gave close results.
\end{abstract}

To Cite: Arslan H., Üneş F., Demirci M., Taşar B., Yılmaz A. Estimation of Keban Dam Lake Level Change Using ANFIS and Support Vector Machines. Osmaniye Korkut Ata Üniversitesi Fen Bilimleri Enstitüsü Dergisi 2020; 3(2): 71-77.

\section{Giriş}

Günümüzde küresel iklim değişikliğinden kaynaklanan belirsizlikleri içeren yağış, giriş ve çıkış hidrografı gibi hidrolojik verileri tahmin etmek günümüz şartlarında zaman, maliyet ve iş gücü bakımından zor olmaktadır. Baraj hazne işletme çalışması, suyun zaman içindeki birikimini ve salınımını belirleyen bir dizi k1sıt ve kararları gerektirmektedir. Hazne seviyesinin doğru tespiti ve tahmini, hazne yönetiminde ve işletilmesinde daha iyi kararların alınmasına yardimc kaynaklarının yönetimini optimize etmekle kalmaz, aynı zamanda bir haznenin güvenliğini de sağlar. Hazne kapasitesini belirleme üzerine ilk 
çalışmalar, Ripple [1] ve Sudler [2] tarafindan klasik yöntemler kullanılarak yapılmıştır.

Adaptif Sinirsel Bulanık Çıkarım sistemi (ANFIS) modelleri geçmişte inşaat mühendisliğinde, su kaynakları ve yönetiminde birçok kez kullanılmıştır. Keskin ve ark. [3], Türkiye'deki günlük buharlaşmayı tahmin etmek için bulanık modeller kullanmışlardır. Kazeminezhad ve ark. [4], Ontario Gölü'ndeki dalga parametrelerini tahmin etmek için ANFIS metodunu kullanmış ve ANFIS'i, Kıy1 Mühendisliğinde kullanılan Manuel yöntemlerden daha üstün bulmuşlardır. Kisi [5], günlük buharlaşma tahmini için ANFIS tekniğini uygulamış ve sonuçları değerlendirmiştir. Kisi ve Öztürk [6], evapotranspirasyon tahmini için ANFIS hesaplama yöntemini kullanmışlardır. Üneş ve ark. [7], Missouri Nehrine ait katı madde değişimlerini Destek vektör makineleri modeli kullanarak tahmin etmiştir. Özdülkar ve ark. [8], bulanık mantık tekniklerini (ANFIS) kullanarak göldeki buharlaşma miktarını belirlemişlerdir. Demirci ve ark. [9] ve Üneş ve Demirci [10], baraj hazne seviyesi ve yer altı suyu değişiminin tahmini için değişik yapay sinir ağları modelleri kullanmışlardır. Demirci ve ark. [11], Amerika'daki Stony Brook baraj hazne hacminin tahmini için ANFIS metodunu kullanmışlardır.

Compolo ve ark. [12], yapay sinir ağı modeli kurarak yoğun yağış esnasında nehir taşkın modelini oluşturmuşlarıdır. Minns ve Hall [13], bir seri deney verisine dayanarak sentetik veriler üreterek yağış akış ilişkisini incelemişleridir. Tokar ve Johnson [14], yapay sinir ağ kullanarak Maryland'deki Little Patuxent nehir havzası için günlük yağış, sıcaklık ve kar erimesi verilerini kullanarak oluşan günlük akıșı tahmin etmişleridir. Üneş ve ark. [15], günlük baraj hazne seviye değişimlerini yapay zekâ yöntemleri kullanarak tahmin etmişlerdir. Taşar ve ark. [16], günlük baraj haznesinde ölçülen buharlaşma miktarının tahmini için yapay sinir ağı modelini kullanmışlardır. Üneş ve ark. [17], yapay zekâ teknikleri ve ampirik yöntemlere dayalı olarak günlük buharlaşmayı tahmin etmişlerdir. Üneş ve ark. [18], genelleştirilmiş regresyon yapay sinir ağları modeli ile baraj hazne hacmi tahmininde bulunmuşlardır.

$\mathrm{Bu}$ sunulan çalışmada, Keban Baraj gölünün günlük su seviyesi değişimini tahmin etmek için ÇDR, ANFIS ve DVM yöntemleri kullanılmış ve elde edilen sonuçlar gerçek gözlem verileri ile değerlendirilmiştir.

\section{Materyal}

\section{1. Çalışma Alanı}

Keban Baraj Gölü, Türkiye'nin en büyük yapay gölüdür (Şekil 1). $675 \mathrm{~km}^{22}$ lik alanı ile göller arasında üçüncü sırada yer almaktadır. Baraj Gölü uzunluğu 125 km'dir. Elektrik üretiminin yanı sıra Keban Baraj Gölünde su balıkçılığı ve balık üretimi de yapılmaktadır. Türkiye, enerji açısından ilk büyük yatırımlardan biridir. İnşaatı 1965 'te başlamıştır. 1974'te ilk 4 tribün ve 1981 'de diğer 4 tribün inşa edilmiştir. Barajın toplam kurulu gücü 134 Megawatt ve yıllık enerji üretimi 7,5 Milyar KW/Saat'tir. Tesis enerji üretimine başladığında Türkiye'de üretilen elektriğin $\% 20$ 'lik kısmını üretmekte olup, günümüzde de tüketilen toplam elektriğin önemli bir kısmını karş1lamaktadır [19].

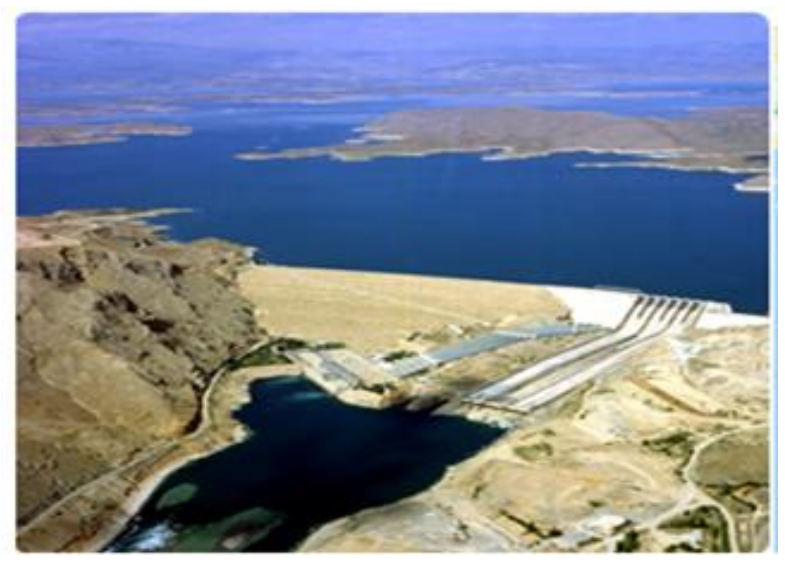

Şekil 1. Keban Baraj1 Genel Görünümü

Keban barajının inşasından sonra 64,100 hektar büyüklüğünde bir baraj gölü meydana gelmiștir. Elâzı̆̆ çevresinde ve göl çevresindeki çevre illerde rekreasyon ve rekreasyon alanları bulunmaktadır. Şekil 2'de barajın Türkiye'deki konumu verilmiştir.

Keban Baraj Gölü maksimum su seviyesi ve doluluk oranı yüksek değerlere sahip olan su yapılarındandır. Hidrolojik su yılı içerisinde önemli mevsimlik su seviye değişimleri göstermektedir. Keban baraj1, enerji üretiminin yanı sıra sulama ve balıkçılık gibi farklı amaçlar için de kullanılmaktadır. 


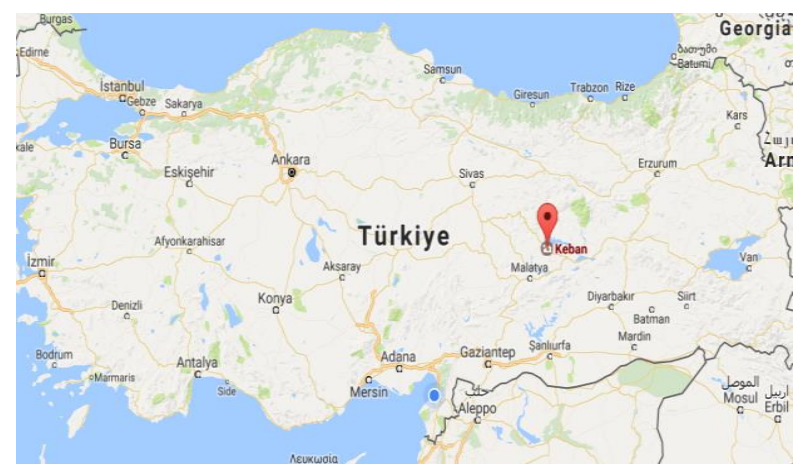

Şekil 2. Keban Barajının Konumu

\section{Metod}

\section{1. Çoklu Lineer Regresyon (ÇLR)}

ÇLR modeli, bağımlı bir değişken ile bir veya daha fazla bağımsız değişken arasındaki doğrusal ilişkiyi modellemek için kullanılan bir yöntemdir. ÇLR modelinin genel denklemi şu şekilde ifade edilir:

$$
\mathrm{y}=\mathrm{a}+\mathrm{b}_{1} \mathrm{x}_{1}+\mathrm{b}_{2} \mathrm{x}_{2}+\ldots \ldots \ldots \ldots+\left(\mathrm{b}_{\mathrm{m}} \mathrm{x}_{\mathrm{m}}\right)
$$

$\mathrm{Bu}$ denklemde $\mathrm{y}$ beklenen değeri temsil eder. $\left(\mathrm{x}_{1}\right.$, $\left.\mathrm{x}_{2}, \ldots, \mathrm{x}_{\mathrm{m}}\right)$ bağımsız parametreleri göstermektedir.

\subsection{Destek Vektör Makineleri}

Destek vektör makineleri (DVM), Cortes ve Vapnik [20] tarafindan kurulan veri odaklı araştırma alanlarında makine öğrenme yaklaşımıdır. DVM istatistiksel öğrenme teorisine dayanmaktadır. DVM temel olarak iki veri sinıfi arasında en iyi ayrım yapmak için kullanılmaktadır. Bu amaçla karar sınırları veya hiper düzlemler belirlenmektedir. Doğrusal olmayan bir veri kümesinde, DVM'ler doğrusal bir hiper düzlem çizememektedir. Bu nedenle Kernel çekirdek kullanılmaktadır. Kernel Çekirdek yöntemi, doğrusal olmayan verilerdeki makine öğrenimini büyük ölçüde artırmaktadır. DVM tahmincisinin (y) işlemi şu şekilde ifade edilmektedir:

$$
\mathrm{y}=\left(\mathrm{K}_{\mathrm{xi}} \cdot \mathrm{W}_{\mathrm{jk}}\right)+\mathrm{b}
$$

Kernel Çekirdek işlevi $\mathrm{K}_{\mathrm{xi}}$ ise, b SVM ağının bias/önyargı terimidir ve $\mathrm{W}_{\mathrm{jk}}$ ağırlık vektörü olarak adlandırılmaktadır. $\mathrm{K}_{\mathrm{x}}$ ve $\mathrm{W}$, Lagrange çarpanlarını göstermektedir. $\mathrm{K}_{\mathrm{xi}}$, giriş vektörlerini yüksek boyutlu bir özellik alanına eşleyen doğrusal olmayan bir fonksiyondur. Kernel Çekirdek $\left(\mathrm{K}_{\mathrm{xi}}\right)$ çeşitli fonksiyon çözümleriyle belirlenmektedir. Bu çalışmada radyal tabanlı fonksiyon ile analiz yapılmıştır. Çıktı verileri için eğitim veri setlerinin önemini elde eden Lagrange çarpanları. Doğrusal olmayan radyal tabanlı fonksiyon [21] yöntemine ait denklem şu şekilde ifade edilebilmektedir:

$$
\begin{aligned}
& \mathrm{K}_{\mathrm{xi}}=\mathrm{e}^{-\gamma\left\|\mathrm{p}_{\mathrm{i}}-\mathrm{y}_{\mathrm{i}}\right\|^{2}} \\
& \gamma>0 \text { ve } \mathrm{i}=1,2,3, \ldots \mathrm{n}
\end{aligned}
$$

Burada $\mathrm{K}_{\mathrm{xi}}$ doğrusal olmayan bir fonksiyondur, $\gamma$ kullanıc tanımlı bir parametredir, $p_{i}$ ve $y_{i}$ girdi uzayındaki vektörlerdir.

\subsection{Bulanık Mantık}

Bulanık Mantık teorisi ilk olarak Zadeh [22] tarafından öne sürülmüsstür. $\mathrm{Bu}$ yöntem günümüzde birçok farklı disiplinde değişik problemler için yaygın olarak kullanılmaktadır. Yöntemde, bilgi ve tecrübeye dayalı olarak girdi ve çıktı parametrelerinin bulanık kümeleri oluşturularak, bulanık kurallara dayalı ilişkiler kurulur, elde edilen bulanık çıktı kümesinden durulaştırma adı verilen işlem ile istenilen çıktı değerleri belirlenerek Bulanık Modeller oluşturulmaktadır. Literatürde, bulanık kümelerin belirlenerek, seçilen kurallara dayalı durulaştırma işleminin uygulanmasında kullanılan en yaygın ve pratik yöntemlerden birisi de Takagi-Sugeno tarafından önerilen bulanık çıkarım sistemine dayalı Adaptif Sinirsel Bulanık Çıkarım sistemi (Adaptive Neuro-Fuzzy Inference System, ANFIS) adı verilen bulanık mantık yöntemidir. 1993 yılında Jang [23] tarafindan geliştirilen ANFiS modeli, Hibrit öğrenme algoritması kullanmaktadır. Yapay sinir ağları ve bulanık çıkarım sistemi birleșiminden oluşmaktadır. Bu çalışmada Bulanık Mantık modelinin oluşturulması ve çözümünde ANFIS modeli kullanılmıştır.

\section{Model Sonuçları ve Değerlendirmeler}

İki yıllık gözlem verileri dikkate alınarak Çoklu Lineer Regresyon analizi (ÇLR), Destek Vektör Makineleri (DVM) ve Adaptif Sinirsel Bulanık Çıkarım sistemi (ANFIS) için modeller oluşturulmuştur. ANFIS, DVM ve ÇLR modellerinde kullanılan toplam 731 verinin 511 verisi eğitim için 220 verisi de test için uygulanmıştır. Model ile elde edilen sonuçlar ölçüm değerleri ile karşılaştırılmıştır. Her bir model için ortalama karesel hataların karekökü (KOHK), ortalama mutlak hata $(\mathrm{MOH})$ ve gözlemlenmiş değerler arasındaki determinasyon 
katsayıları $\left(\mathrm{R}^{2}\right)$ belirlenerek karşılaştırılmıştır. $\mathrm{KOHK}, \mathrm{MOH}$ ve $\mathrm{R}^{2}$ değerlerine göre model performansları değerlendirilmiştir. KOHK ve $\mathrm{MOH}$ aşağıdaki gibi denklemlere göre belirlenmiştir.

$$
\mathrm{KOHK}=\sqrt{\frac{1}{\mathrm{~N}} * \sum_{\mathrm{i}=1}^{\mathrm{N}}\left(\mathrm{GSS}_{\text {gözlenen }}-\mathrm{GSS}_{\text {tahmin }}\right)^{2}}
$$

ve

$$
\mathrm{MOH}=\frac{1}{\mathrm{~N}} * \sum_{\mathrm{i}=1}^{\mathrm{N}}\left|\mathrm{GSS}_{\mathrm{gözlenen}}-\mathrm{GSS}_{\mathrm{tah} \min }\right|
$$

Burada, N veri sayılarını ve GSS baraj hazne göl su seviyesi verilerinin gözlenen ve tahmin değerlerini göstermektedir. Sunulan çalışmada Keban barajının enerji gayesi için su sarfiyatı, günlük toplam su sarfiyatı, toplam buharlaşma miktarı kullanılarak ve geçmiş ölçümlerden elde edilen bir zaman ötelenmiş hazne seviyesi $(\mathrm{t}+1)$ kullanılarak, günlük hazne seviyesi değişimi tahmin edilmiştir. ÇLR modelinin oluşturulmasında kullanılan girdi veri seti, ANFIS ve DVM modelin eğitim ve test aşamasında uygulanmıştır.

ÇLR, DVM ve ANFIS modellerinin performans değerlendirmesi için determinasyon katsayısı $\left(\mathrm{R}^{2}\right)$, karesel hataların karekökü (KOHK), ortalama mutlak hata $(\mathrm{MOH})$ kullanılmıştır. Test verilerinden elde edilen KOHK, MOH ve $\mathrm{R}^{2}$ parametrelerinin karşılaştırılması Çizelge 1'de gösterilmektedir.

Cizelge 1. CLR, ANFIS ve DVM Modellerinin Performans Karşılaştırılması

\begin{tabular}{l|c|ccc}
\hline Model & Model & KOHK & MOH & $\mathbf{R}^{2}$ \\
İsimleri & Girdileri & $(\mathbf{m})$ & $(\mathbf{m})$ & \\
\hline ÇLR & EGSS, & 0,53 & 0,58 & 0,98 \\
DVM & $\begin{array}{c}\text { TSS, } \\
\text { TB, }\end{array}$ & 0,03 & 0,03 & 0,99 \\
ANFIS & GSS $_{\mathrm{t}+1}$ & 0,02 & 0,01 & 0,99 \\
\hline
\end{tabular}

Burada Göl su seviyesi $\left(\mathrm{GSS}_{\mathrm{t}}\right)$ tahmin analizleri için, "EGSS" günlük enerji gayesi için su sarfiyatın1, "TSS" günlük toplam su sarfiyatını, "TB" günlük toplam buharlaşmayı ve " $\mathrm{GSS}_{\mathrm{t}+1}$ " günlük ötelenmiş göl su seviyesini ifade etmektedir.

\section{1. Çoklu lineer regresyon (ÇLR) Sonuçlart}

$\mathrm{Bu}$ çalışmada yukarıda tanımlanan veri kümesi için Çoklu Lineer Regresyon modeli için elde edilen hata ve ilişki sonuçları Çizelge 1'de verilmiştir. ÇLR analizi ile elde edilen denklem aşağıda verilmiştir:

$\mathrm{y}=8,64+2,73 \times 10^{-9} \times$ EGSS $+1,84 \times 10^{-8} \times \mathrm{TB}-$
$2,26 \times 10^{-10} \times \mathrm{TSS}+0,97 \times \mathrm{GSS}_{\mathrm{t}+1}$

Şekil 3'te, test süreci için, elde edilen ÇLR modeli ile elde edilen günlük baraj hazne seviyesi tahminleri ve ölçüm değerleri karşılaştırılmıştır. Test verileri için ÇLR tahmin sonuçları ile ölçüm değerlerinin saçılma diyagramı Şekil 4'te verilmiştir.

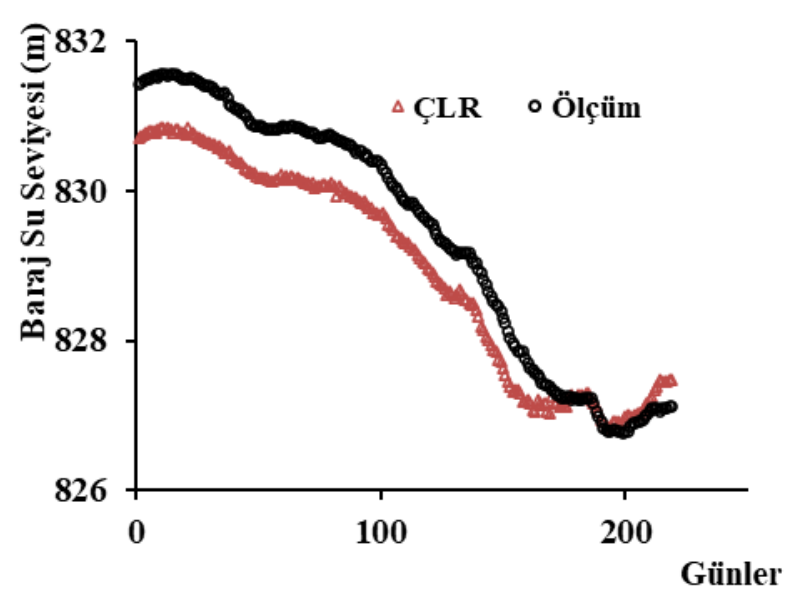

Şekil 3. 2 yıllık baraj hazne seviyesi test verileri için Ölçüm ve ÇLR dağılım grafiğgi

ÇLR analizi için; Keban barajına ait günlük enerji gayesi için su sarfiyatı (EGSS), günlük toplam su sarfiyatı (TSS), günlük toplam buharlaşma (TB) miktarı kullanılarak ve günlük geçmiş ölçümlerden elde edilen bir zaman ötelenmiş göl su seviyesi $\left(\mathrm{GSS}_{\mathrm{t}+1}\right)$ kullanılarak, günlük hazne seviyesi değişimi tahmin edilmiştir.

Şekil 3’te dağılım grafiğginde de görüleceği gibi ÇLR değerleri ile gerçek ölçüm değerler arasında çok güzel bir uyumluluk olduğu görülmektedir. Şekil 4'de görüldüğü gibi ÇLR model için $\mathrm{R}=0,99$ determinasyon katsayısı elde edilmiştir. Buda model sonuçların gerçek ölçüm değerleri ile uyumluğunu açık bir şekilde göstermektedir. 


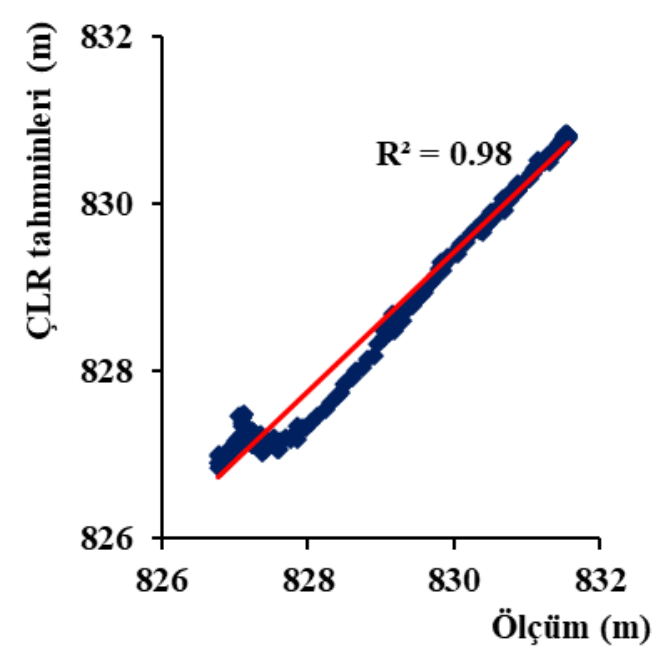

Şekil 4. 2 yıllık baraj hazne seviyesi test verileri için Ölçüm ve ÇLR saçılım grafiği

\section{2. Destek Vektör Makineleri (DVM) Sonuçları}

DVM analizi için; ÇLR analizindeki parametreler kullanılmış ve Keban barajına ait günlük enerji gayesi için su sarfiyatı (EGSS), günlük toplam su sarfiyatı (TSS), günlük toplam buharlaşma (TB) miktarı kullanılarak ve günlük geçmiş ölçümlerden elde edilen bir zaman ötelenmiş göl su seviyesi $\left(\mathrm{GSS}_{\mathrm{t}+1}\right)$ kullanılarak, günlük hazne seviyesi değişimi tahmin edilmiştir.

DVM modeli için doğrusal olmayan radyal tabanlı fonksiyon (RTF) kullanılmıştır. DVM modelinin $\mathrm{R}^{2}$, KOHK ve $\mathrm{MOH}$ terimlerinin test istatistiği Çizelge 1'de sunulmuştur.

$\mathrm{Bu}$ çalışma için kurulan ANFIS modelinde test verileri için ayrı ayrı tahmin sonuçları ve gözlemlenen baraj hazne seviyeleri için dağılım ve saç1lım grafikleri Şekil 5 ve 6'da verilmiştir.

DVM modeli 2 y1llık veriler için değerlendirilmiş ve determinasyon katsayıs1, elde edilen sonuçlardan $\mathrm{R}^{2}=0,99$ olarak elde edilmiştir. DVM test aşaması için tahmini değerleri ÇLR ve ANFIS değerlerine yakın sonuçlar vermiştir. Çizelge 1'den ve aşağıdaki şekillerden de görüldüğü gibi, DVM modeli test verileri için uygulandığında $0,99^{\prime}$ luk bir determinasyon ve oldukça düşük hata değerleri ile haznedeki günlük su seviyesi tahmin edilebilmiștir. Bütün veriler ve olayın fiziği dikkate alındığında, DVM modelinin ÇLR ve ANFIS metodu ile uyumlu ve birbirine yakın sonuçlar verdiği görülmüştür.

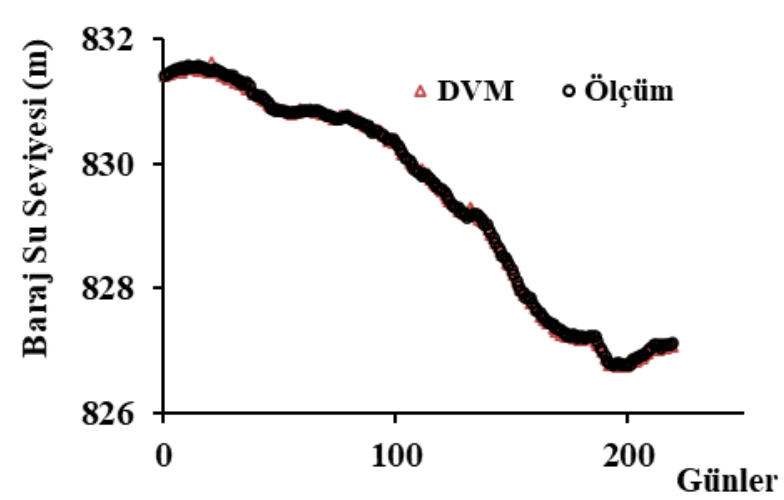

Şekil 5. Baraj hazne seviyesi test verileri için Ölçüm ve DVM dağılım grafiği

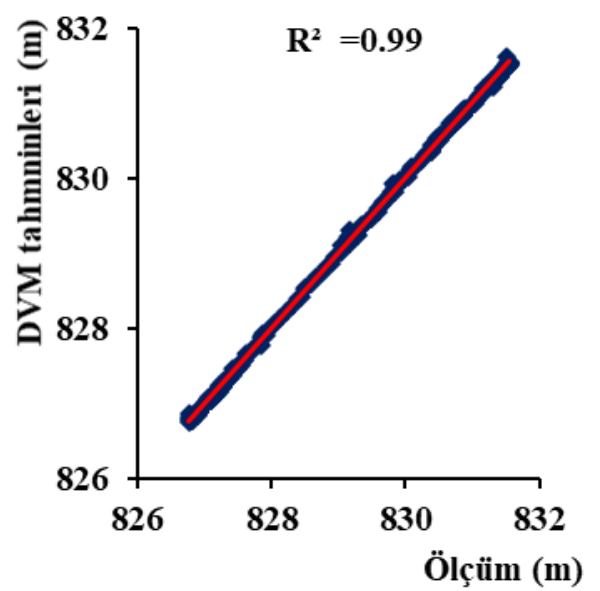

Şekil 6. Baraj hazne seviyesi test verileri için Ölçüm ve DVM saçılım grafiği

\section{3. Adaptif Sinirsel Bulanık Çıkarım Sistemi (ANFIS) Sonuçlart}

ANFIS analizi için; ÇLR-DVM analizlerindeki parametreler kullanılmış ve Keban barajına ait günlük enerji gayesi için su sarfiyatı (EGSS), günlük toplam su sarfiyatı (TSS), günlük toplam buharlaşma (TB) miktarı kullanılarak ve günlük geçmiş ölçümlerden elde edilen bir zaman ötelenmiş göl su seviyesi $\left(\mathrm{GSS}_{\mathrm{t}+1}\right)$ kullanılarak, günlük hazne seviyesi değişimi tahmin edilmiştir.

ANFIS modeli, ölçülen günlük hazne verilerini kullanarak hazne seviyesini tahmin etmek için MATLAB (ANFIS) hazır programı kullanılmıș ve matlab dilinde bir ilave kod yazılarak sonuçlar değerlendirilmiștir. ANFIS modelinin $\mathrm{R}^{2}$, KOHK ve $\mathrm{MOH}$ terimlerinin test istatistiği Çizelge l'de sunulmuştur.

$\mathrm{Bu}$ çalışma için kurulan ANFIS modelinde test verileri için ayrı ayrı tahmin sonuçları ve gözlemlenen baraj hazne seviyeleri için dağılım ve saçılım grafikleri Şekil 7 ve 8 'de verilmiştir. ANFIS modelleri 2 y1llık veriler için değerlendirilmiş ve determinasyon katsayısı, elde edilen sonuçlardan $\mathrm{R}^{2}=0,99$ olarak elde edilmiştir. ANFIS test aşaması için tahmini 
değerleri ÇLR değerlerine yakın sonuçlar vermiştir. Çizelge 1'den ve aşağıdaki şekillerden de görüldüğü gibi, ANFIS modeli test verileri için uygulandığında 0,99 'luk bir determinasyon ve oldukça düşük hata değerleri ile haznedeki günlük su seviyesi tahmin edilebilmiştir. Bütün veriler ve olayın fiziği dikkate alındığında, ANFIS modelinin ÇLR metodu ile uyumlu ve birbirine yakın sonuçlar verdiği görülmüştür.

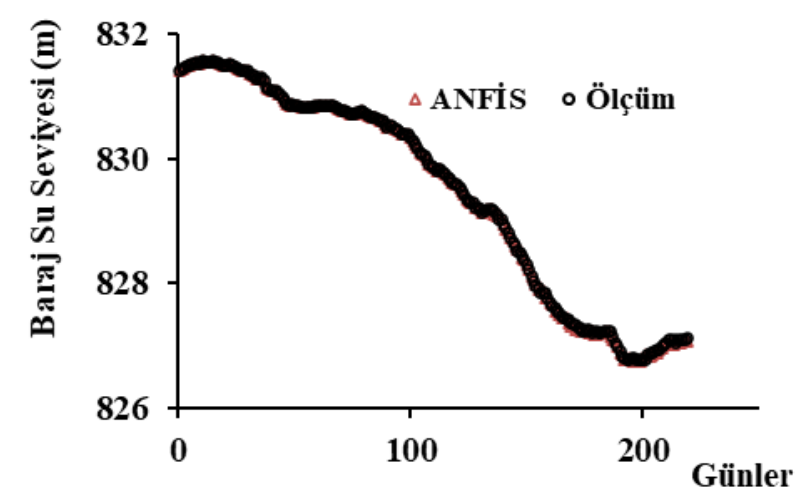

Şekil 7. Baraj hazne seviyesi test verileri için Ölçüm ve ANFIS dağılım grafiği

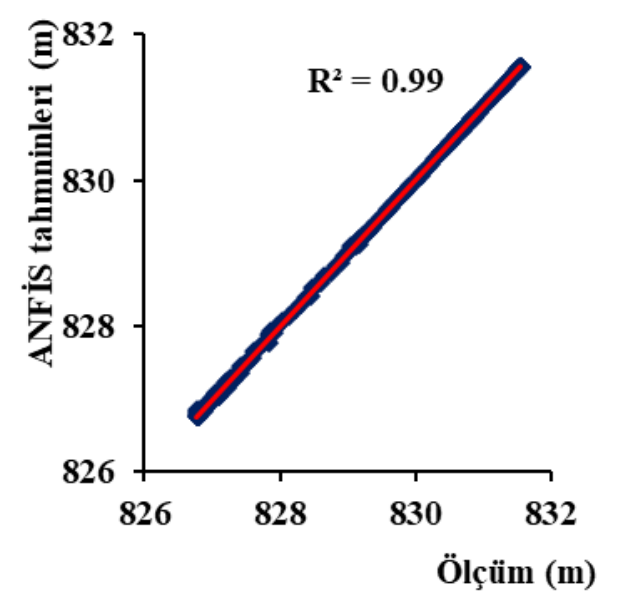

Şekil 8. Baraj hazne seviyesi test verileri için Ölçüm ve ANFIS saçılım grafiği

\section{SONUÇLAR}

$\mathrm{Bu}$ çalışmada, Keban barajına ait günlük enerji gayesi için su sarfiyatı (EGSS), günlük toplam su sarfiyatı (TSS), günlük toplam buharlaşma (TB) miktarı kullanılarak ve günlük geçmiş ölçümlerden elde edilen bir zaman ötelenmiş göl su seviyesi $\left(\mathrm{GSS}_{\mathrm{t}+1}\right)$ kullanılarak, günlük hazne seviyesi değişimi tahmin edilmeye çalışılmıştır. Baraj gölü seviyesini tahmin etmek için Çoklu Lineer Regrasyon (ÇLR), Bulanık Mantık (ANFIS) ve Destek Vektör Makineleri (DVM) modelleri kullanılmıştır. Yapılan bu çalışma için aşağıdaki sonuçları türetmek mümkündür.

- ÇLR modeli ampirik ilişkileri açıklamakla birlikte, parametreler arasında lineer ilişki olması nedeniyle iyi sonuçlar verdiği düşünülmektedir.

- DVM modeli, baraj gölü seviye değişiminde geleneksel ÇLR modeline yakın sonuçlar vermiştir. Hata miktarları açısından değerlendirildiğinde az da olsa DVM modelinin daha iyi tahmin değerleri verdiği gözlenmiştir. Aralarında lineer ilişki olmayan değişkenler için DVM modelleri iyi sonuçlar verebilmektedir.

- ANFIS modeli baraj gölü seviye değişiminde yüksek ilişki ve düşük hata performansı göstermiştir. Geleneksel ÇLR modeli ve DVM modeline göre daha düşük hataya sahiptir. ANFIS modeli gerek lineer gerekse lineer olmayan durumlar için olayın fiziğini yansitabildiğinden iyi tahminler elde edilebilmektedir.

Sonuçlar göstermektedir ki, seçilen bir hazne için bir ANFIS ve DVM modeli geliştirildiğinde, günlük hazne seviye değiş̧imi, hidroelektrik enerji hesaplamaları ve su kaynakları yönetiminin belirlenmesi su kaynakları yönetimi çalışmalarında bu elde edilen model sonuçları kullanılabilecektir. Keban Baraj haznesinin seviye tahmininde seçilen her üç modelde birbirine çok yakın sonuçlar ile doğru tahminde bulunmuşlardır. $\mathrm{Bu}$ manada her üç modelinde baraj seviye tahmininde kullanılabileceği düşünülmektedir.

\section{Teşekkür}

Bu çalışmada Devlet Su İşleri (DSI) tarafından ölçülen hidrolojik veriler kullanılmıştır. Yazarlar, adı geçen kuruma desteklerinden dolayı teşekkür eder.

\section{Kaynakça}

[1] Ripple W. The capacity of storage for water supply, Proc., Institution of Civil Engineers $1883 ; 71,270$.

[2] Sudler CE. Storage required for regulation of streamflow, Trans., ASCE 1927; 91, 622.

[3] Keskin ME., Terzi O., Taylan D. Fuzzy logic model approaches to daily pan evaporation estimation in Western Turkey, Hydrological Sciences Journal 2004; 49, 1001-1010. 
[4] Kazeminezhad MH., Etemad-Shahidi A., Mousavi SJ. Application of fuzzy inference system in the prediction of wave parameters, Ocean Engineering 2005; 32, 1709-1725.

[5] Kisi O. Daily pan evaporation modeling using a neuro-fuzzy computing technique, Journal of Hydrology 2006; 329, 636-646.

[6] Kisi O., Ozturk O. Adaptive neurofuzzy computing technique for evapo-transpiration estimation, Journal of Irrigation and Drainage Engineering 2007; 133, 368-379.

[7] Üneş F., Karaeminoğulları AB., Taşar B. Forecasting of river sediment amount using machine model, International Journal of Environment, Agriculture and Biotechnology 2020; 5(1): 9-15.

[8] Özdülkar K., Üneş F., Demirci M., Kaya YZ. Günlük buharlaşma miktarının bulanık mantık yöntemleri kullanılarak bölgesel olarak modellenmesi, Osmaniye Korkut Ata Üniversitesi Fen Bilimleri Enstitüsü Dergisi 2019; 2(1): 23-29.

[9] Demirci M., Unes F., Kaya YZ., Mamak M., Tasar B., Ispir E. Estimation of groundwater level using artificial neural networks: a case study of Hatay-Turkey, In 10th International Conference Environmental Engineering. 2017

[10] Üneş F., Demirci M. Generalized regression neural networks for reservoir level modeling, International Journal of Advanced Computational Engineering and Networking 2015; 3, 81-84.

[11] Demirci M., Unes F., Kaya YZ., Tasar B., Varcin H. Modeling of dam reservoir volume using adaptive neuro fuzzy method, Aerul si Apa. Componente ale Mediului, 2018; 145-152.

[12] Campolo M., Andreussi P., Soldati A. River flood forecasting wiht a neural network model, Water Resour. Res. 1999; 35(4): 1191-1197.

[13] Minns AW., Hall MJ. Artificial neural networks as rainfall-runoff models, Hydrologic Science 1996; 41(3): 399-417.
[14] Tokar AS., Johnson PA. Rainfall-runoff modeling using artificial neural networks, J. Hydrologic Engrg., ASCE 1999; 4(3): 232239.

[15] Üneş F., Demirci M., Taşar B., Kaya Y Z., Varçin H. Estimating dam reservoir level fluctuations using data-driven techniques, Polish Journal of Environmental Studies 2019; 28(5): 3451-3462.

[16] Taşar B., Üneş F., Demirci M., Kaya YZ. Yapay sinir ağları yöntemi kullanılarak buharlaşma miktarı tahmini, DÜMF Mühendislik Dergisi 2018; 9(1): 543-551.

[17] Unes F., Kaya YZ., Mamak M. Daily reference evapotranspiration prediction based on climatic conditions applying different data mining techniques and empirical equations, Theoretical and Applied Climatology 2020; 141, 763-773.

[18] Üneş F., Demirci M., Taşar B., Kaya Y Z., Varçin H. Modeling of dam reservoir volume using generalized regression neural network, support vector machines and M5 decision tree models. Applied Ecology and Environmental Research 2019; 17(3):70437055 .

[19] Devlet $\mathrm{Su}$ İşleri Genel Müdürlüğü, http://www.dsi.gov.tr/

[20] Cortes C., Vapnik V. Support-vector networks, Machine learning 1995; 20(3): 273-297.

[21] Hsu CW., Chang CC., Lin CJ. A practical guide to support vector classification. 2003.

[22] Zadeh LA. Fuzzy sets, Information and Control 1965; 8, 338-353.

[23] Jang JS. ANFIS: Adaptive-network-based fuzzy inference system, IEEE transactions on systems, man, and cybernetics 1993; 23(3):665-685. 